\title{
Pocket IPCC
}

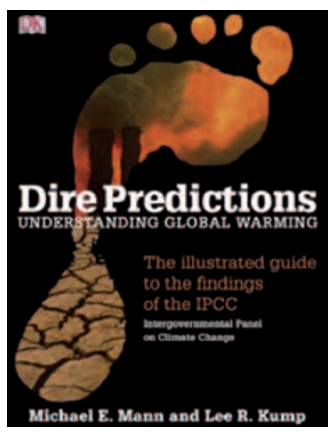

\section{DIRE PREDICTIONS: UNDERSTANDING GLOBAL WARMING, THE ILLUSTRATED GUIDE TO THE FINDINGS OF THE IPCC}

\author{
by Michael E. Mann and Lee R. Kump
}

DK Adult: 2008. 208pp. US\$25

\section{The hefty 2007 report from the Intergovernmental Panel on Climate Change gets a diminutive translation.}

In spite of the best efforts of the many scientists who make up the Intergovernmental Panel on Climate Change (IPCC) to produce policyrelevant assessments, decision-makers generally find its reports mysterious and inaccessible; even the summaries for policymakers are daunting for most non-scientists. This simple fact makes my job necessary - I work with decision-makers in various sectors to help them grasp the science and projected impacts of climate change. But I am only a bridge between them and the IPCC's authoritative assessments. Many times, during a round-table discussion with business leaders or a briefing with policymakers, I have wished I had copies of the panel's reports handy, but it is impractical to lug around three books the size of the Los Angeles telephone directory.

Now climatologists Michael Mann and Lee Kump offer a solution to my dilemma in their diminutive translation of the most recent IPCC report, Dire Predictions: Understanding Global Warming, the Illustrated Guide to the Findings of the IPCC. This lavishly illustrated volume is little more than a centimetre thick and fits neatly in the outer pocket of my backpack, which goes wherever I go. It covers most - though not all - of the key concepts and conclusions of the panel's reports. The main tool of communication and by far the best feature of the book is its high-quality data graphics showing the key observations and projections from which the IPCC developed its conclusions. As a complement to this feature, the nearly 70 topics in the book are covered succinctly, most in just two pages each. Complex concepts of key importance are given additional space. For instance, climate sensitivity and attribution modelling each get eight pages, and the explanations are probably the best I have seen on these difficult topics for the lay reader. All other subjects are covered in four or fewer pages. This format is accessible and amenable to either topical referencing or reading through.

When I first picked up Dire Predictions, I wondered why we needed another climate change primer. The Rough Guide to Climate Change by Robert Henson and the companion book to Al Gore's An Inconvenient Truth both do a good job of covering the most important topics relating to the science of climate change. However, I was soon convinced that Dire Predictions fills an important new niche as a companion to the IPCC report written by real scientists who know what the process is all about. The authors are respected climatologists who bring authority and deep understanding to the genre, yet they wisely forego any focus on their own scientific contributions, such as Mann's 'hockey stick' reconstruction of past climate, which became a political flashpoint in the US Congress in 2006. Another distinction of Dire Predictions is that its structure hews close to that of the three IPCC working groups. Parts 1 and 2 cover the basic science (IPCC Working Group I), while Parts 3 and 4 cover impacts, vulnerability and adaptation (IPCC Working Group II) and Part 5 covers mitigation of greenhouse gas emissions (IPCC Working Group III).

Although comprehensive, Dire Predictions is uneven in its coverage. I felt as though I had read two books, one where the basic science and solutions to climate change were treated thoroughly and supported effectively with data, and another, more haphazard treatment of climate impacts that made assertions but provided little data to back them up. Part 3 in particular short-changes the IPCC's group on impacts and adaptation, which reported what was arguably the biggest breakthrough finding of the panel's 2007 assessment - the attribution of worldwide physical and biological impacts to human-induced global warming. This blockbuster finding is not mentioned in Dire Predictions, and the short impacts section generally seemed out of date. I also felt that there were too many typos and small mistakes in the prose.

My one other significant complaint is that the authors forego any discussion of the controversial projections of sea level rise published in the 2007 IPCC report. Instead, they favour projections published later by the German climatologist Stefan Rahmstorf. By avoiding the legitimate scientific debate about future sea level rise, the authors miss a golden opportunity to educate the public and policymakers about the scientific process. The IPCC's projections - a 18- to 59-centimetre rise for the twenty-first century - were based largely on modelled expansion of ocean water as it warms, neglecting the likely future acceleration of freshwater discharge from land-based ice sheets. Rahmstorf's projections of 50 to 140 centimetres, which potentially captured both thermal expansion and ice-sheet contributions to future sea level rise, properly imply that sea level rise could be much greater than one would surmise from the IPCC report.

In spite of some flaws, I found Dire Predictions unique in its IPCC-centric organization, rich with accessible and well-presented data, and largely successful in its attempt to demystify the voluminous reports in a small footprint. At its best, this little book 
opens up the world of climate science by showing the real data in accessible formats and by addressing key uncertainties. Its coverage of IPCC Working Groups I and III is outstanding, and I hope to see a second edition soon that does equal justice to Working Group II. I would also like to see the topics cross-referenced to the IPCC reports and an appendix of cited literature. A true guide to the IPCC assessment should offer the invested reader an entrée to the actual reports and the literature they probe.

I look forward to pulling out my 'Pocket IPCC' the next time I encounter a sceptical businessman or a congressional staffer who needs to know more about climate projections or the uncertainty surrounding climate sensitivity. It might even impress my friends at cocktail parties.
Published online: 9 0ctober 2008

doi:10.1038/climate.2008.109

\section{Jay Gulledge}

Jay Gulledge is a Senior Scientist and

Program Manager for Science \& Impacts at the Pew Center on Global Climate Change in Arlington, Virginia.

e-mail:gulledgej@pewclimate.org

\section{On our bookshelf: dark visions}

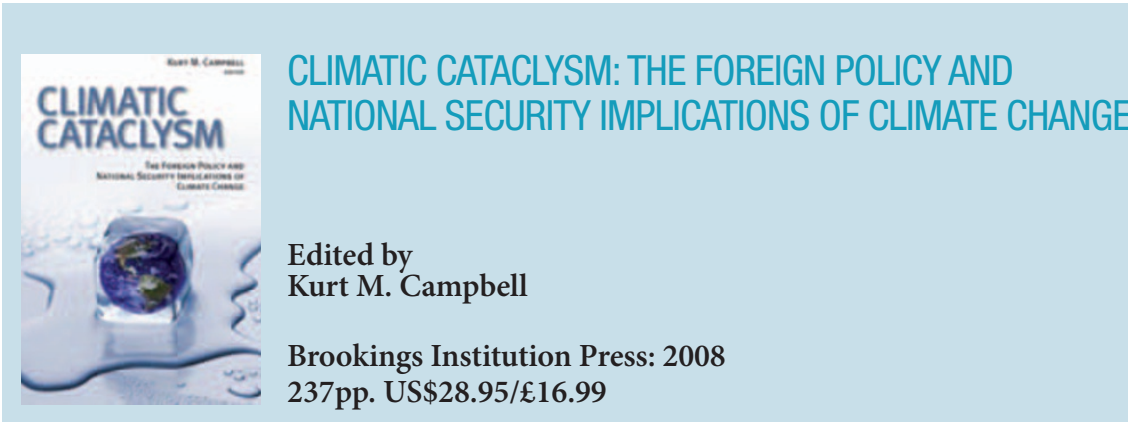

Crossing the terrain of science, society, fiction and futurism, a new crop of books imagines harrowing possible fates for humans in a greenhouse world. Among these varied narratives, Climatic Cataclysm stands out for its impressive $\mathrm{CV}$, originating in two years of discussions among 20 eminent experts on climate science, foreign policy and national security. Distilled from their talks are three possible scenarios of an altered Earth, ranging from the likely best case to the worst. In the first, moderate emissions cause warming of $1.3^{\circ} \mathrm{C}$ above the 1990 global average by 2040 , in line with the latest projections from state-of- the-art climate models. The second scenario pictures the temperature rise accelerated by feedback effects, and the third has the Earth passing a devastating tipping point later this century, producing cataclysmic change.

Acknowledging the great uncertainties in their projections but aiming for farsightedness, the authors soberly detail expected impacts and potential human responses. On their list are not just famine and pestilence but class war, the collapse of economies and the United Nations, and plummeting developed-world birthrates owing to "increasingly difficult living conditions and ... general loss of hope".

\section{THE LONG DESCENT: A USER'S GUIDE} TO THE END OF THE INDUSTRIAL AGE

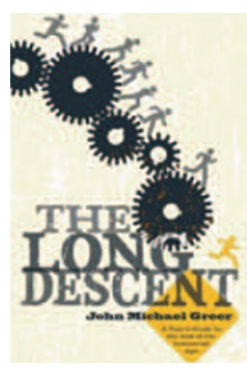

by John Michael Greer

New Society

Publishers: 2008

288pp. US\$18.95

\section{The Long Descent collects and} expands on essays by peak-oil blogger John Michael Greer, whose writing draws on his historical expertise and spiritual sensibility: Greer holds the title of Archdruid. He believes that climate change and energy shortages will bring on societal collapse, but not the kind many fear. Our culture's most deeply felt visions of the future - on one hand, irrepressible progress, and on the other, sudden catastrophe - are literally myths, Greer argues, with the same defining features as myths in other cultures. The reality will be the long, stepwise deterioration of the book's title, one that mirrors the decline of past civilizations.

That means a rapidly approaching global crisis decades long, followed by a recovery but then further crises. Each step in Greer's descent strips the human population of social and technological complexity, and the sequence ends with regression to a sustainable agrarian regime that none of us will live to see. His advice: neither global nor personal action can prevent this long descent, but a grassroots shift toward low-tech, low-energy and communityoriented lifestyles would soften the immediate blow.

\section{THE CARBON DIARIES 2015}

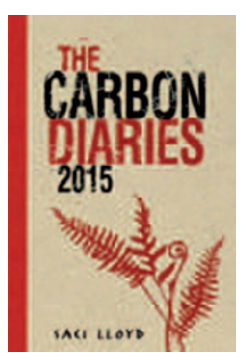

by Saci Lloyd

Hodder Children's

Books: 2008

384pp. $£ 6.99$

In this novel, a teenage girl's irreverent journal entries are the window into a society scrambling for footing in the face of climate change. With disastrous weather pounding the globe, the United Kingdom in 2015 becomes the first country to seize control of emissions with a comprehensive carbon-rationing scheme. To ride the bus, charge a phone or buy a bottle of Australian wine requires a swipe of the electronic ration card - and the only resort when credits run out is the black market. 